\title{
Anthropometric Patterns and Correlates of Growth Attainment in Under-five Pakistani Children
}

\begin{abstract}
SABIHA IBRAHIM
This study investigates the question whether socio-economic, demographic and environmental variables within a household will affect the growth patterns of under-five Pakistani children. It also examines whether there are differentials in the growth patterns of these children by age and gender. Using the 1990-91 Demographic and Health Survey data, the focus is on children under-five years, the total children identified were 5902 while anthropometric measurement to assess the growth status was available for 4079 children. The results showed that nearly all the socio-demographic, economic and environmental variables were significantly associated with $\mathrm{H} / \mathrm{A}$ and $\mathrm{Wt} / \mathrm{A}$. Children most likely to be stunted and underweight were those whose mothers were aged 40-44 years, mothers with no education, children from rural areas and children with birth interval $<24$ months. The multivariate analyses for Height/A model showed succeeding birth interval $>24$ months, mother's age, her education and having toilet facilities in the house positively associated with growth attainment. For the Weight/A model succeeding birth interval $>24$ months, mother's age, her education and having toilet facilities and electricity in the house, and living in Punjab and NWFP province positively associated with growth attainment. This study will be useful for policy-makers to develop programmes and guidelines needed to improve those socio-economic, demographic and environmental factors, responsible for the poor nutritional status of children under-five years of age in Pakistan.
\end{abstract}

\section{INTRODUCTION}

Growth, a physiological feature of infancy, childhood and adolescence is the interaction of genetics and environmental circumstances involving wide spectrum of metabolic processes. Growth assessment is the single best measurement for defining the health and nutritional status of children, and changes in these factors invariably affect growth potentials [De Onis et al. (1992)]. The common indicators to measure growth attainment are height-for-age $(\mathrm{Ht} / \mathrm{A})$, weight-for-age $(\mathrm{Wt} / \mathrm{A})$ and weight-forheight $(\mathrm{Wt} / \mathrm{Ht})$. Children's weight and height increase as they get older. These Islamabad.

Sabiha Ibrahim is Research Demographer at the Pakistan Institute of Development Economics,

Author's Note: The preliminary research for this paper was undertaken at demography programme at the Australian National University, Canberra, as part of the MA research work. I am extremely thankful to Dr Christine McMurray, Demography Department at the ANU, for her useful comments, continuous support and encouragement throughout the research work at ANU. In addition, I would like to thank Dr G. M. Arif, Senior Research Demographer at PIDE for his valuable comments on an earlier version of this paper, and to the anonymous referees of this journal. 
measurements are therefore expressed in relation to the growth patterns of a reference population to allow for proper comparison of the measurements of children at different ages.

Growth attainment studies undertaken in the Asian continent indicate 97 million children under-five years having low nutritional status which increases their risk of dying before the first birthday by four times, as compared with children from other continents [UNICEF (1997)]. Furthermore, children under-five years from South-Asia have the lowest nutritional status (Appendix Table 1). Estimates based on the International Reference Standard of American and Pakistani children shows that the Pakistani children are only 75 percent in weight-for-age, and 86 percent in height-for-age as compared to American children [Pakistan (1978)].

Poor nutritional status are generally referred as 'Stunting' (Ht/A) to indicate long term malnutrition, 'Underweight' (Wt/A) to indicate present malnutrition and Wasting $(\mathrm{Ht} / \mathrm{Wt})$ to indicate chronological and on-going malnutrition. The few nutritional surveys conducted in Pakistan over time have indicated poor growth status among children under-five years of age. The 1976-77 Micro-Nutrient Survey (MNS) showed children to be 43 percent low height-for-age, 39 percent underweight and 10 percent low weight-for-height. The 1985-87 Nutrition Survey (NS) showed children to be 46 percent low height-for-age, 48 percent underweight and 15 percent low weight-for-height. The IFPRI Rural Surveys of Pakistan conducted between 1986-87 and 1988-89 indicated 62 percent low height-for-age and 9 percent low weight-for-height. Moreover, the 1990-91 Demographic Health Survey (DHS), showed children to be 49 percent low height-for-age, 40 percent underweight and 9 percent low weight-for-height.

Previous micro and macro studies on growth differentials of under-five Pakistani children have focused mainly on the issue of micro-nutrient deficiencies, or inadequacy of supplementary diets or the medical phenomena (i.e. genetic variations, growth behaviour etc.). Therefore the gap that this study fills and its contribution to the literature on the subject lies in its investigation into the question whether socio-economic, demographic and environmental variables within a household affect the growth patterns of Pakistani children under-five years of age? If yes, which of these factors are the most significant and what are the future policies needed for improving them?

The study also examines the growth patterns by age and gender, as earlier research done on child health status has shown higher female mortality during the postnatal and childhood period [Sathar (1985)]. This will help answer if the high female mortality is a result of poor growth attainment or some other reasons such as discrimination in health care or feeding habits among the genders in Pakistan [Mull (1991)]. This study will be useful for policy-makers in developing programmes and guidelines needed to improve those socio-economic, demographic and environmental factors responsible for the poor nutritional status of children under-five years of age in Pakistan. 
Following the introduction, Section 2 reviews the existing literature on those socio-economic, demographic and environmental variables that contribute to poor growth. Section 3 refers to the hypotheses developed that will be tested throughout this study. Methodology adopted for this study is discussed in Section 4. The sample characteristics of the selected socio-demographic, economic and environmental variables are examined in Section 5. Section 6 analyses the age-gender differentials in the growth patterns. Section 7 on Methods of Analysis identifies other growth differentials: firstly the association of the anthropometric indicators and the selected variables within the sample; secondly, the association of each of the independent variables while controlling the effects of the other independent variables in the $\mathrm{Ht} / \mathrm{A}$ and $\mathrm{Wt} / \mathrm{A}$ model, to determine their relative strength and importance. The final Section 8 discusses the conclusion and policy recommendations.

\section{REVIEW OF LITERATURE}

There is a large body of literature on the relationship between the anthropometric indicators and the selected socio-demographic, environmental and economic variables. Some of the studies point to the direct and indirect effects of a mother's education on a child's growth attainment. One direct effect is that educated mothers are more capable of utilising the available household resources to improve the health of children. An indirect effect is that education tends to be correlated with economic advantage, so educated mother's provide superior environment and nourishment to their children [Caldwell et al. (1983)]. Therefore education of women and girls can play a vital role in improving the nutritional status of children, if there is some freedom of movement, awareness about the available health facilities and knowledge of what constitutes a proper diet for children. A study done in Pakistan [Alderman and Garcia (1993)] showed that mothers with only primary level education had less than half as many wasted children as mothers with no education (4 percent compared with 9 percent), and fewer stunted children (57 percent compared with 62 percent). Whereas a Nepalese study showed that maternal schooling was a predictor for stunting but not for wasting, indicating that long-term nutritional patterns and health status are more likely to be affected by maternal schooling than short-term patterns [Joshi (1994)].

Another factor most strongly associated with poor growth attainment is birth interval [Sanaurer and Garcia (1991)]. First, the mother is less likely to regain her full strength from the last birth and may not be physically prepared for the next birth. This may mean that the newborn child has a low birth weight and is at greater risk of becoming ill [Lutter et al. (1990)]. Second, if mothers are not able to take adequate care of several young children because of the excessive demands they make, all of the children are exposed to greater risk of illness and making recovery from illness and catching up in weight longer. Thirdly, insufficient parental time and family 
resources can disadvantage children as much as deliberate discrimination in feeding [Sanaurer and Garcia (1991) and Harton (1988)].

Several studies of child growth in South Asian countries have found evidence of differences by gender. The common belief in relation to discrimination in food allocation in the developing countries, particularly in South Asia, is that mothers feel boys have greater nutritional needs because they will do more strenuous work than girls. They also consider that boys are the bread winners and old age supporters of parents, while girls will not contribute to household income as they will leave the household after marriage [Ahmed and Khuda (1986); DasGupta (1987) and Muhuri and Preston (1991)]. Another belief is that high-protein food such as eggs and meat may lead to early puberty among girls [UNICEF and Pakistan (1992)]. A study from Bangladesh focusing on children 4-14 months found no gender differentials in growth or discrimination in feeding [Brown et al. (1982)], but concluded that feeding discrimination was more likely after the age of 18 months.

The Matlab study in Bangladesh of early 1970s, which used the sex-specific Harvard Wt/A standards for children less than 5 years, found 14 percent of girls were severely malnourished as compared to 5 percent of boys. While 59 percent of the girls were measured as being moderately malnourished, only 55 percent of boys were moderately malnourished. The results for $\mathrm{Ht} / \mathrm{A}$ were similar [Chen et al. (1981)]. The Indian Narangwal study of 1970-73 showed that girls were significantly shorter and lighter than boys at ages 1-36 months [Kielmann (1975)]. A study on marasmus in children from the Punjab and Sindh provinces in Pakistan found no difference in the number of cases by gender, but there were more and early deaths of girls than boys. This may be because the girls' illnesses were treated at a later stage than boys' illnesses [Mull (1991)]. Another study by Alderman and Garcia (1994) on Pakistani children found no differences in feeding practices and growth patterns of children by gender.

It is generally agreed that socio-demographic factors have greater impact on growth retardation than ethnic factors, socio-economic strata, or geographical areas especially for children under-five years of age. Habicht et al. (1974) found that, overall, the preschool child's growth in terms of height and weight is more affected by environmental than by ethnic factors. Their study showed that generally children from various ethnic groups, socio-economic strata and geographical areas tended to grow uniformly in length and weight during the first 3-6 months of life. After six months those in developing countries tended to lag behind those from developed countries. Eveleth and Tanner's (1996) study of African children and adults of various ethnic groups showed greater differences within ethnic groups living in different environments than between ethnic groups in the same environment. However, within any particular ethnic and social group, inherited genetic 
characteristics produce differentials in growth attainment [Mueller (1986)]. In the case of Pakistan, beside nutrition geography may also affect growth status of preschool children. Balochistan is the driest province and the least fertile area, while Punjab is the most fertile agricultural area in Pakistan [Pakistan (1992)].

\section{HYPOTHESES}

From the preceding discussion of selected studies the specific hypotheses that has been developed in this study to test the importance of socio-demographic, environmental and economic factors on the growth patterns of children under age five are:

1. Age is positively correlated with stunting and underweight;

2. Stunting and underweight is not gender specific among children;

3. The more educated the mother, the lower the incidence of stunting and underweight in children;

4. The higher the birth order, the higher the incidence of stunting and underweight in children; and

5. The better the economic well-being and environment of the household, the lower the incidence of stunting and underweight.

\section{METHODOLOGY}

The data used in this paper is from 1990-91 Pakistan Demographic and Health Survey (PDHS II). Sample weights were used for the households to allow for the differentials in probability of selection in the four provinces, and to make the sample representative for the whole of Pakistan. The sample consisted of 7,193 households, with interviews of 6,611 women aged 15-49 years and 1,354 men (who were their husbands). The children aged 0-24 months were measured in a supine position on an adjustable wooden measuring board; the same board was used to measure the heights of older children while they were standing. Hanging spring scales were used to measure the weights of the children 0-24 months, and standard-measuring scales were used for those children who could stand.

As the study is primarily focused on children, a child file was created to identify the total number of children present in the survey, which were 27,396 in total. From these aged 0-59 months numbered 5902, and anthropometric measurement to assess growth was available for 4079 children. While interpreting the results of this paper it is important to understand that cross sectional data takes growth attainment of many children, rather than one individual child at one point of time [McMurray (1996)] and because this study compares growth of children 0-59

months with the standard reference child of the same age and gender at the time of 
survey, it does not look at growth over a period and therefore does not show growth trends over time. Therefore health status of individual children cannot be determined nor can we find those children who were normally healthy, but at the time of survey were ill and rapidly losing weight.

A possible limitation affecting the results of this study is the relatively high proportion of eligible children that could not be measured (31 percent) which has reduced the sample size. This is because of the traditional attitudes of mothers or the geographical location. As shown in Appendix Table 2 the percentage of children that could not be measured by age was the highest for mothers refusing to get the child measured ( 30 percent). The refusal of mothers is based on the traditional belief in the evil eye or nazar lagna, especially if it is the first born or less than six months old or a boy [Pakistan (1992)]. For those children living in Balochistan province the small number of eligible children being measured is because of the overall economic under-development of the province as compared to the other province. ${ }^{1}$ The other possible limitation is data that are not available for all the husbands. Therefore, it was necessary to exclude father's characteristics from the analysis in order to avoid severe reduction of the sample size and the possible introduction of sampling bias. Evidence from earlier research shows that father's characteristics are less important in comparison to mother's characteristics in explaining growth patterns among Pakistani children [Alderman and Garcia (1994)]. However, the low percentage of eligible children measured in this study, is not a cause of alarm as non-response rates of over 20 percent among children under age five is common in DHS anthropometry data set.

\section{SAMPLE CHARACTERISTICS}

The socio-demographic, economic and environmental variables selected for this study are based on their importance in the literature reviewed. The variables are age in months (0-59) and gender of child, the child's birth order and birth interval, mother's age and her education, region, province, sources of drinking water, type of sanitation, provision of electricity and television in the house.

In Appendix Table 3, the percentage distribution of children that are measured is lower among mother's in the age group of 15-19 and $>40$ years. This could be because the mean age of first marriage in Pakistan is 19 years, and the majority of births occurring are between ages 20-39 years [Pakistan (1992)]. Or this may be due to young mothers' hesitation to allow their first child to be measured (17 percent), while mother's $>40$ years may not have children under five years of age to be measured. The percentages of children measured in age less than one year and the first birth are low, reinforcing the argument made earlier that traditional attitudes of mothers show that they are hesitant to have strangers measure their young ones. The

\footnotetext{
${ }^{1}$ The calculation for children that have not been measured by age and province is not shown but is available with the author.
} 
main area of inconsistency is by province, with substantially smaller percentages of children measured in Balochistan, the poorest province in Pakistan [UNICEF (1992)], than in other provinces. Overall, 10 percent of eligible children in Balochistan were measured, compared with 29 percent in Sindh, which is more urbanised and economically developed. The low number of children measured in Balochistan has to be kept in mind while interpreting the results. This underrepresentation in the least developed province is reflected in smaller percentages of rural children (46 percent). The same is true for children in households without electricity, television and reliable water and sanitation.

\section{GROWTH PATTERNS}

World Health Organisation (WHO) recommends that a child's weight and height be expressed in terms of the number of standard deviations (SD) that a child's measurement (weight or height) deviates from the median value of the international reference population for children of the same age and gender. At the population level or for the subgroup of children, these measures are referred to as Z scores [Dibley et al. (1987)]. The anthropometric indicators for a normal population is usually a bell-shaped symmetric distribution, while for the population in developing countries they are skewed to the left of normal distribution of the reference median, with a degree of overlapping [Mora (1989)]. Percentage of children whose Z-score falls below a defined cut-off point namely, minus 2SD from the median of the international reference population identifies children who have poor nutritional status. Therefore, minus 2SDs is used as the cut-off point to identify children aged 0-59 months who are at risk of poor growth attainment in this paper, as it is considered to be the most widely referred to cut-off standard. A common pattern of growth in individual children in developing countries is low $\mathrm{Ht} / \mathrm{A}$, normal or low $\mathrm{Wt} / \mathrm{A}$ and normal $\mathrm{Wt} / \mathrm{Ht}$. Of the three conditions, wasting is the most severe, and children seldom remain long in a wasted state, as they tend either to recover or to deteriorate further and die.

Table 1 shows the percentage of children by age measured according to their anthropometric characteristics, the results show that there are 51 percent children stunted, 40 percent children underweight and 8 percent wasted in the study population. It can be seen that the stunted percentage increases sharply at age 12-23 months and then continues to increment gradually. The pattern for children who are underweight shows that there is a sharp increase among those at the age 6-11 months and more children are underweight than being stunted at this age group. A possible explanation could be their vulnerability to infections and their diets that is inadequately supplemented after age six months. The pattern for wasting, however, is quite different, with substantially larger percentages between ages 6 and 23 months than at older ages. 
Table 1

Children Aged 0-59 Months Measured by Anthropometric Categories, Pakistan 1990-91

(Percent)

\begin{tabular}{lcccc}
$\begin{array}{l}\text { Children } \\
\begin{array}{c}\text { Measured } \\
\text { Age }\end{array}\end{array}$ & Stunted (\%) & Underweight (\%) & Wasted (\%) & Total \\
\hline $0-5$ & 17.8 & 13.6 & 7.4 & 456 \\
$6-11$ & 28.4 & 33.3 & 11.2 & 447 \\
$12-23$ & 53.8 & 42.5 & 10.6 & 833 \\
$24-35$ & 56.8 & 45.3 & 7.3 & 844 \\
$36-47$ & 64.8 & 44.6 & 6.7 & 823 \\
$48-59$ & 64.2 & 46.7 & 4.8 & 676 \\
Total & $\mathbf{5 1 . 5}$ & $\mathbf{4 0 . 0}$ & $\mathbf{8 . 0}$ & $\mathbf{4 0 7 9}$ \\
\hline
\end{tabular}

Source: Computed from Pakistan Demographic and Health Survey 1990-91 data.

\section{(a) Overall Anthropometric Distribution Pattern}

The distribution of Z-scores for samples of children of different ages can be appreciated more easily if they are plotted as curves which can be compared with a normal curve [Dibley et al. (1987); Waterlow et al. (1977)]. It is important to note that when plotted curves depict data from cross-sectional surveys such as PDHS II, they show patterns for the sample as a whole and do not give information on the growth trends of individual children [McMurray (1996)].

Figure 1 shows the distribution of anthropometric measurements compared to a normal distribution curve, for all the measured children aged 0-59 months. It shows that both $\mathrm{Ht} / \mathrm{A}$ and $\mathrm{Wt} / \mathrm{A}$ curves are close to a normal curve but shifted to the left, relative to the median of the reference population. The Ht/A curve is displaced furthest to the left of the reference median. It is interesting that the medians $\mathrm{Ht} / \mathrm{A}$ and $\mathrm{Wt} / \mathrm{A}$ are almost the same, as many countries display a pattern in which the median $\mathrm{Wt} / \mathrm{A}$ is closer than the median Ht/A to the reference median [McMurray (1996)]. This is a possible reason that the $\mathrm{Wt} / \mathrm{Ht}$ curve is centered close to the reference median, although somewhat taller and narrower than a normal distribution. The curve for $\mathrm{Wt} / \mathrm{Ht}$ reflects the very small numbers -2 SDs or more below the reference median, as already indicated in Table 1, where only 8 percent were classified as wasted. Now that we have compared the overall anthropometric distribution pattern to a normal distribution (Figure 1) for the sampled population it would be interesting to compare the mean $\mathrm{Ht} / \mathrm{A}, \mathrm{Wt} / \mathrm{A}$ and $\mathrm{Wt} / \mathrm{Ht} \mathrm{Z}$-scores for each age in months.

Figure 2 depicts the $\mathrm{Z}$ scores for $\mathrm{Ht} / \mathrm{A}, \mathrm{Wt} / \mathrm{A}$ and $\mathrm{Wt} / \mathrm{Ht}$ for all measured children for each one month of age. The reference median at each age is shown as a horizontal line, showing variations in the deviation from the reference median with age. 


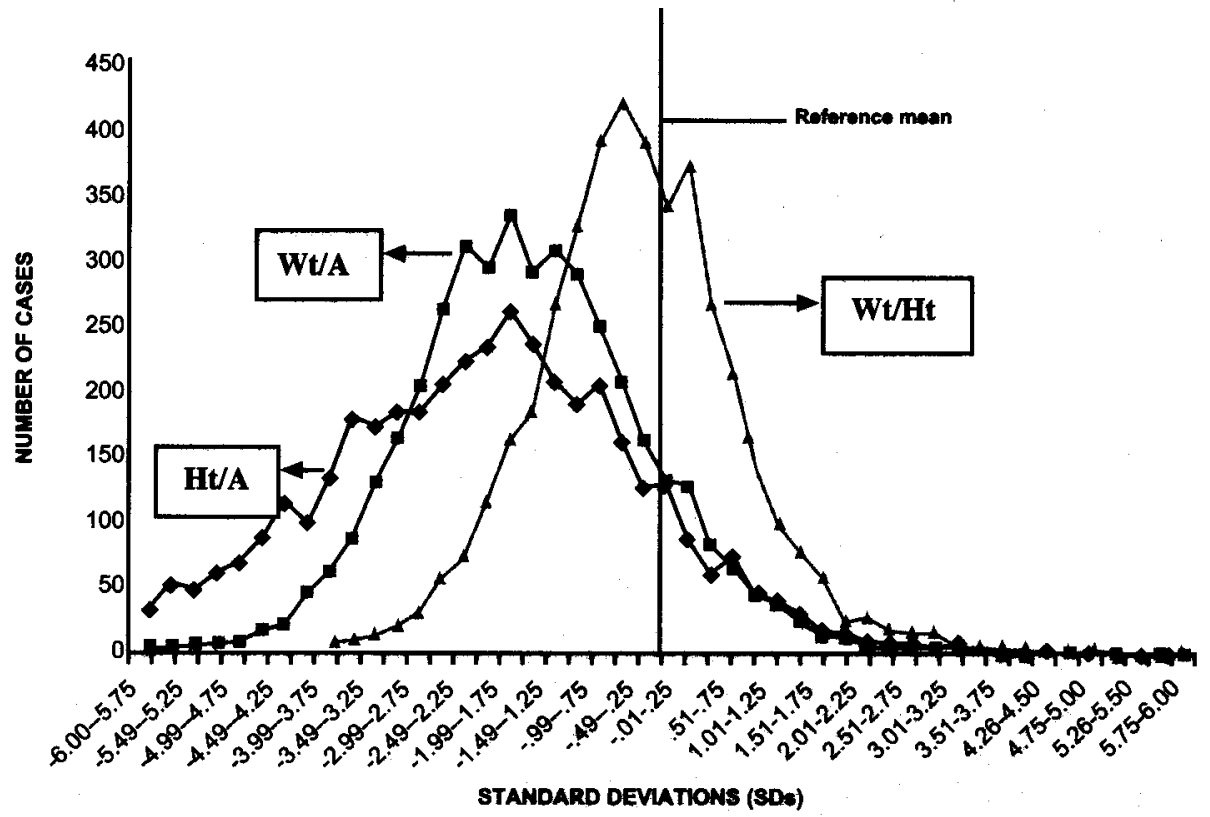

Fig. 1. Overall Ht/A, Wt/A and Wt/Ht Distribution of Children Aged 0-59 Months: Pakistan 1990-91.

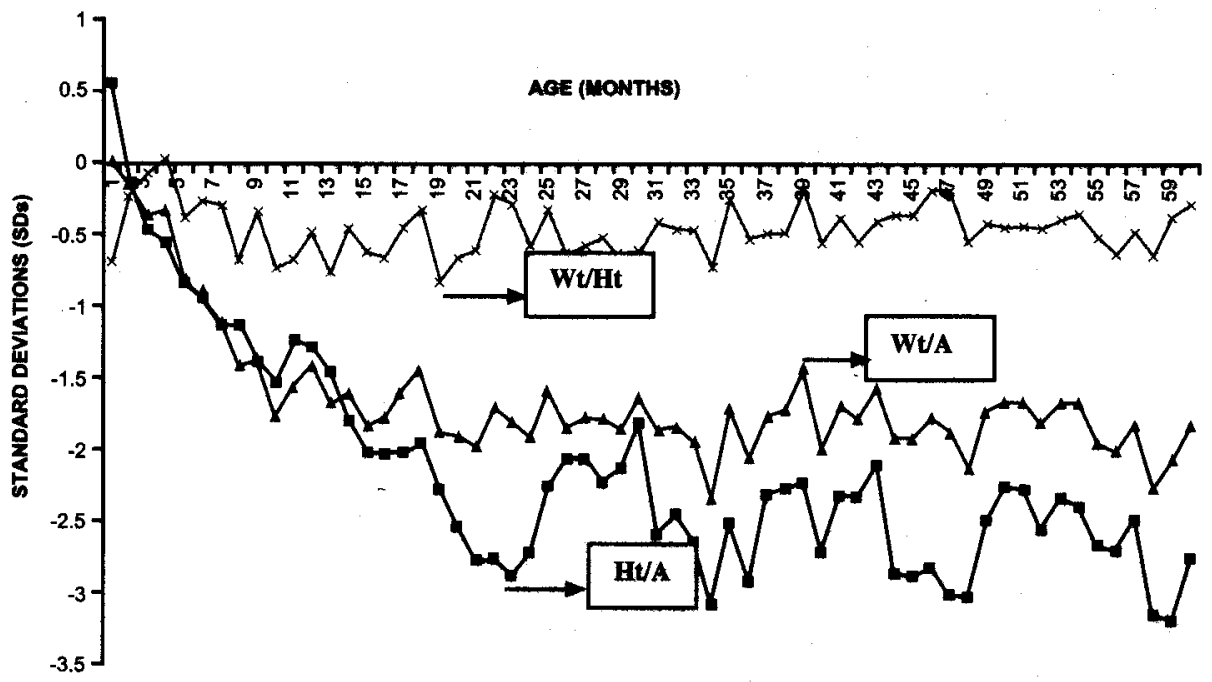

Fig. 2. Pattern of Mean Ht/A, Wt/A and Wt/Ht by Age in Months of All Children Aged 0-59 Months: Pakistan 1990-91. 
It can be seen that at very young ages the Ht/A of sampled Pakistani children was actually above the reference median, but declines sharply with age. As in Figure 1 the patterns for $\mathrm{Wt} / \mathrm{A}$ and $\mathrm{Ht} / \mathrm{A}$ are similar, but the curve for $\mathrm{Wt} / \mathrm{Ht}$ remains close to the reference median. The extent of deviation from the reference median is greatest for $\mathrm{Ht} / \mathrm{A}$, less so for $\mathrm{Wt} / \mathrm{A}$ and very small for $\mathrm{Wt} / \mathrm{Ht}$.

The pattern of growth over time indicates that children are at risk of low Ht/A from 13 to 18 months, but are at greatest risk between ages 21 and 31 months. This tends to be the period following weaning when children have an elevated risk of contracting infections. This is the time when they become mobile and exposed to new environments, that could increase their exposure to contamination. After age 18 months mean Ht/A remains around the level of minus 2 SDs until 59 months without much improvement. The pattern for Wt/A is similar to the pattern for $\mathrm{Ht} / \mathrm{A}$, with mean Wt/A declining markedly from 4 to 9 months and then fluctuating but still tending to decline. There is a sharper decline at 20 months, possibly because this is the period when the majority of Pakistani mothers have stopped breast feeding, and children receive a weaning diet which could be insufficient, or inappropriate or unhygienic while being prepared. The decline at 32 months could signify competition with another sibling born after a short birth interval [Lutter et al. (1990); Gubhaju (1986)]. Mothers with a very young child may not be able to give as much care to older children. Similar results have been found in earlier studies of Bangladesh where the rate of weight increase is normal immediately after birth but then slows at ages 4-6 months and continues to slow relative to the reference standard until 24 months of age [Brown et al. (1982)].

Figure 2 also shows that the mean $\mathrm{Wt} / \mathrm{Ht}$ for each one-month age group is little different from that for the international reference population (straight line at $\mathrm{SDs}=0$ ). This reflects the transient nature of growth faltering with severely wasted children who are either dying or recovering and regaining weight until they return to the normal range [World Health Organisation (WHO) (1986)]. Since a much larger sample of wasted children would be needed to support an exploration of the correlates of wasting, this indicator $(\mathrm{Wt} / \mathrm{Ht})$ is excluded from the remaining analysis in this study.

\section{(b) Age-Gender Growth Patterns}

Figures $2 \mathrm{a}$ and $2 \mathrm{~b}$ plot the mean $\mathrm{Ht} / \mathrm{A}$ and $\mathrm{Wt} / \mathrm{A}$ by age in months separately for males and females aged 0-59 months. Figure 2a shows both boys and girls to be above the reference median Ht/A from birth until age two months. Thereafter there is a sharp decline in $\mathrm{Ht} / \mathrm{A}$, with the mean for boys declining to minus 2 SDs by 16 months and girls reaching this level at 14 months. However, this difference could be an artifact of different sample sizes at each age and cannot be interpreted as hard evidence of a difference by gender. After age 18 months there is considerable fluctuation in $\mathrm{Ht} / \mathrm{A}$, with the mean for girls lowest at ages 22,34 , and 48 months, and 


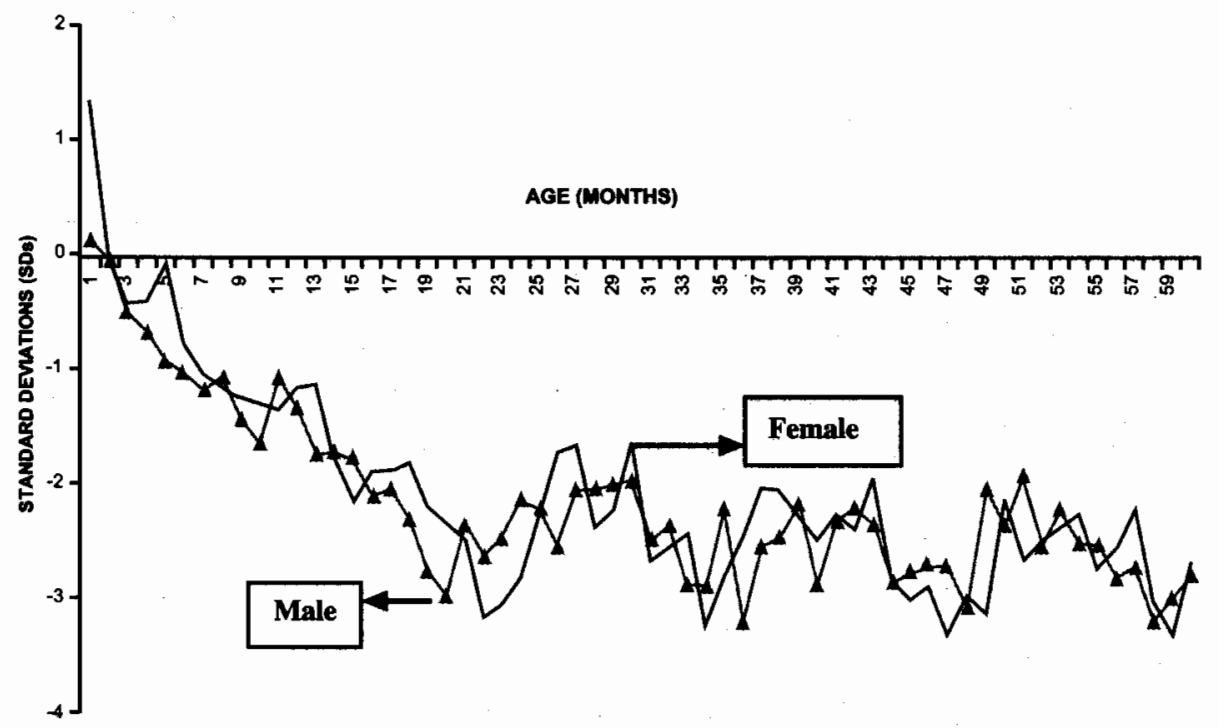

Fig. 2a. Pattern of Mean Ht/A for Male and Female Children Aged 0-59 Months: Pakistan 1990-91.

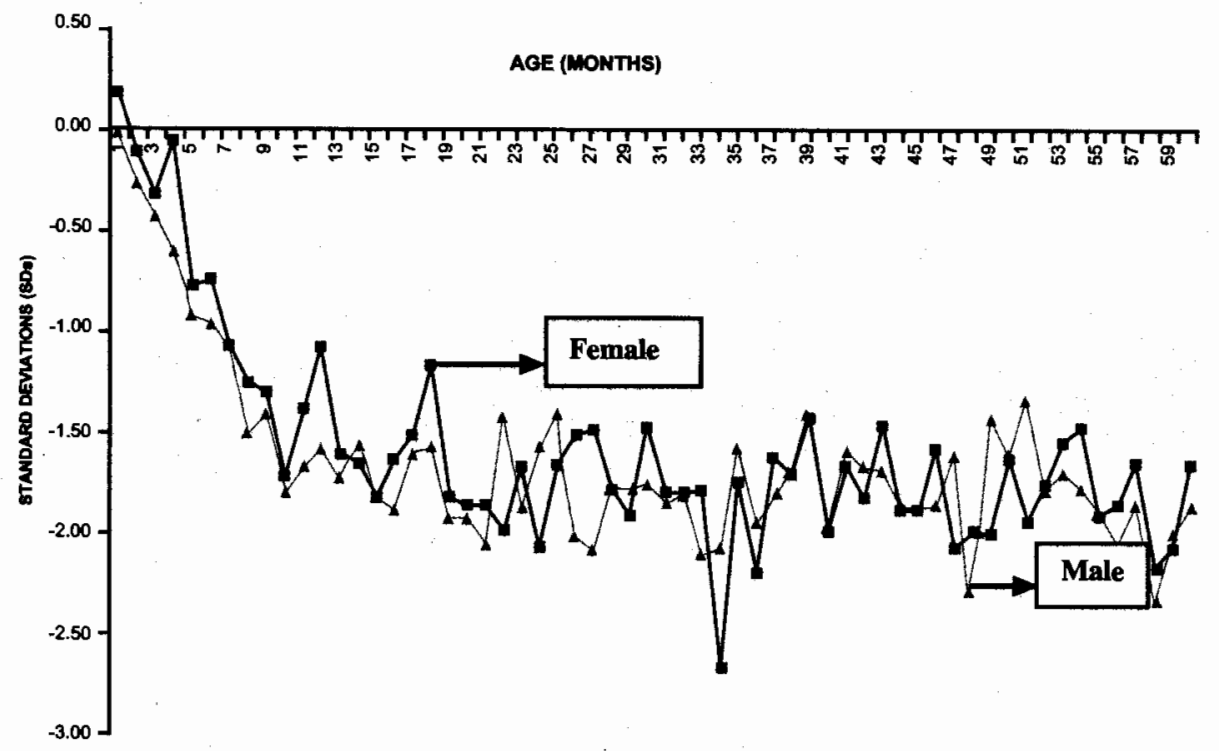

Fig. 2b. Pattern of Mean WtA for Male and Female Children Aged 0-59: Pakistan 1990-91. 
that for boys lowest at 20 and 36 months. Again, these fluctuations are more likely to be due to small and varied numbers in each age group rather than to any consistent difference by gender. There could also be an effect of age mis-reporting or age heaping on 'convenient' numbers such as 6, 12, and 18 months [Pakistan (1992)]. Fluctuations that affect both genders could reflect variations in the seasonal availability of food. Overall, the patterns for both genders in Ht/A are very similar, and there is very little improvement for either boys or girls up to 59 months.

Figure $2 \mathrm{~b}$ shows Wt/A for girls is above the reference median until age two months, and that for boys on the reference median, indicating that girls are relatively heavier than boys in their first few weeks of life. The Wt/A curve for boys then declines sharply, while that for girls both declines and fluctuates. By age 10 months the mean for both boys and girls is around minus 1.75 SDs and thereafter fluctuates around this level, at times sinking below minus 2SDs.

Although the literature indicates that there are gender differentials in child mortality because of differentials in health care and dietary intake, gender differentials in growth attainment are not evident in PDHS II. The nationally representative data used for this analysis may explain why these findings are not the same as those of other studies using smaller regional samples that have shown gender differentials in nutritional status.

\section{METHOD OF ANALYSIS}

\section{(a) Other Differentials of Growth Pattern-Bivariate Model}

In this section firstly the use of simple cross-tabulation has been undertaken to identify associations of the stunting and underweight with the selected socio-economic, demographic and environmental variables for children aged 0-59 months. Some of the variables were re-coded to give meaningful results (mother's age and education, age of children, birth interval and birth order). Toilet facilities and water source both function as a proxy for environmental condition, which do have an indirect association to growth attainment. The results as seen in (Table 2) compare percentage of children at more or less than $-2 \mathrm{SD}$ of the reference population for height-for-age and weight-for-age. Weight-for-height is not used for analysis, as the numbers of children who were wasted were few.

From the earlier discussion (Table 1) we already know that there are more stunted children (51 percent) aged 0-59 months in Pakistan as compared to underweight (40 percent). The result in Table 2 indicates that nearly all the variables are significantly associated with $\mathrm{Ht} / \mathrm{A}$ and $\mathrm{Wt} / \mathrm{A}$, though they have a low Cramer's $\mathrm{V}$ values meaning that although they are significantly different from zero, their relationships are generally weak. 
Table 2

Bivariate Estimates of Percentage Distribution of Height-for-Age and Weight-for-Age for Children Aged 0-59 Months by Socio-demographic Variables, Pakistan, 1990-1991

\begin{tabular}{|c|c|c|c|}
\hline \multirow{3}{*}{$\begin{array}{l}\text { Independent } \\
\text { Variables }\end{array}$} & \multicolumn{2}{|c|}{ Dependent Variables } & \multirow[b]{3}{*}{ Total } \\
\hline & Height-for-Age & Weight-for-Age & \\
\hline & $<-2 \mathrm{SD}$ & $<-2 \mathrm{SD}$ & \\
\hline Mother's Age (Years) $)^{* *}$ & \multicolumn{2}{|c|}{ Mother's Age (Years)* } & \\
\hline $15-19$ & 42.6 & 39.9 & 148 \\
\hline $20-24$ & 50.0 & 38.2 & 796 \\
\hline $25-29$ & 47.3 & 37.2 & 1282 \\
\hline $30-34$ & 54.1 & 40.4 & 906 \\
\hline $35-39$ & 55.3 & 44.4 & 593 \\
\hline $40-44$ & 62.7 & 46.8 & 252 \\
\hline $45-49$ & 57.8 & 42.2 & 102 \\
\hline \multicolumn{2}{|l|}{ Cramer's V 0.10} & Cramer's V 0.06 & \\
\hline Education of Mother** & \multicolumn{3}{|c|}{ Education of Mother** } \\
\hline No Education & 57.8 & 44.4 & 3017 \\
\hline Primary & 44.5 & 38.4 & 440 \\
\hline Secondary/Higher & 25.9 & 19.6 & 622 \\
\hline Cramer's V 0.23 & \multicolumn{2}{|c|}{ Cramer's V 0.18} & \\
\hline Birth Order** & \multicolumn{3}{|c|}{ Birth Order** } \\
\hline 1st Birth & 46.9 & 35.2 & 710 \\
\hline 2nd - 3rd Birth & 46.4 & 36.1 & 1257 \\
\hline 4th -5 th Birth & 52.0 & 40.0 & 1002 \\
\hline 6 th + Birth & 59.9 & 47.3 & 1110 \\
\hline Cramer's V 0.11 & \multicolumn{2}{|c|}{ Cramer's V 0.10} & \\
\hline \multicolumn{2}{|c|}{ Succeeding Birth Interval (Months) ${ }^{* *}$} & \multicolumn{2}{|c|}{ Succeeding Birth Interval (Months)** } \\
\hline First Birth & 46.8 & 35.2 & 710 \\
\hline$<24$ & 55.5 & 44.0 & 1179 \\
\hline $25-47$ & 53.2 & 41.2 & 1121 \\
\hline $48+$ & 45.5 & 35.0 & 1069 \\
\hline Cramer's V 0.07 & \multicolumn{2}{|c|}{ Cramer's V 0.08} & \\
\hline Region** & \multicolumn{3}{|c|}{ Region** } \\
\hline Punjab & 42.1 & 35.5 & 101 \\
\hline Sindh & 54.5 & 46.5 & 1179 \\
\hline NWFP & 56.2 & 36.2 & 1097 \\
\hline Balochistan & 62.7 & 46.5 & 402 \\
\hline Cramer's V 0.14 & \multicolumn{2}{|c|}{ Cramer's V 0.11} & \\
\hline
\end{tabular}


Table $2-($ Continued $)$

\begin{tabular}{|c|c|c|c|}
\hline \multirow{3}{*}{$\begin{array}{c}\text { Independent } \\
\text { Variables }\end{array}$} & \multicolumn{2}{|c|}{ Dependent Variables } & \multirow[b]{3}{*}{ Total } \\
\hline & Height-for-Age & Weight-for-Age & \\
\hline & $<-2 \mathrm{SD}$ & $<-2$ SD & \\
\hline Place of Residence** & \multicolumn{3}{|c|}{ Place of Residence** } \\
\hline Urban & 45.8 & 35.4 & 2190 \\
\hline Rural & 58.2 & 45.2 & 1889 \\
\hline Cramer's V 0.12 & \multicolumn{3}{|c|}{ Cramer's V 0.11} \\
\hline Water Source** & \multicolumn{3}{|c|}{ Water Source** } \\
\hline Piped at Home & 43.0 & 33.4 & 1115 \\
\hline Public Tap & 59.6 & 41.3 & 446 \\
\hline Piped on the Residence & 48.0 & 35.2 & 654 \\
\hline Well with Pump & 53.5 & 45.2 & 1121 \\
\hline Well without Pump & 60.0 & 44.1 & 390 \\
\hline Other & 59.7 & 49.9 & 340 \\
\hline Cramer's V 0.13 & \multicolumn{3}{|c|}{ Cramer's V 0.11} \\
\hline Type of Toilet Facility** & \multicolumn{3}{|c|}{ Type of Toilet Facility** } \\
\hline Flush & 39.8 & 30.7 & 1635 \\
\hline Pit & 59.8 & 43.8 & 448 \\
\hline No Facility/Bush & 60.1 & 48.9 & 1287 \\
\hline Other (Bucket) & 57.8 & 42.0 & 690 \\
\hline Cramer's V 0.20 & \multicolumn{3}{|c|}{ Cramer's V 0.16} \\
\hline Has Electricity** & \multicolumn{3}{|c|}{ Has Electricity** } \\
\hline No & 62.6 & 51.4 & 906 \\
\hline Yes & 48.4 & 36.6 & 3165 \\
\hline Cramer's V 0.12 & \multicolumn{3}{|c|}{ Cramer's V 0.13} \\
\hline Has Television** & \multicolumn{3}{|c|}{ Has Television** } \\
\hline No & 58.8 & 45.3 & 2410 \\
\hline Yes & 41.0 & 32.1 & 1601 \\
\hline Cramer's V 0.17 & \multicolumn{3}{|c|}{ Cramer's V 0.13} \\
\hline
\end{tabular}

Source: This Table is estimated from original analysis of the PDHS 1990-91 data set. *Significant at $\mathrm{p}=<0.05 ; *$ Significant at $\mathrm{p}=<0.01$. NS: Not Significant $\mathrm{p}=>0.05$. 
Children of mothers aged $40-44$ years were most likely to be stunted (63 percent) at 99 percent significance level and underweight (47 percent) at 95 percent level of significance. This could be because older mothers tend to have many children, little education and may not be in good physical health to take proper care of their younger children. Mothers with no education have a higher impact on poor growth, with 58 percent children being stunted and 44 percent underweight.

This result conforms to results from earlier research studies [Pebley and Goldman (1995); Bicego and Boerma (1993) and Martorell et al. (1984)], on the importance of mother's education to child growth. Other statistically significant variable e.g. living in the rural areas shows growth distribution being 58 percent and 45 percent, thus children from the rural areas are shorter than those from urban areas. Provincial difference shows that in Balochistan 63 percent are stunted and 47 percent underweight. The results from demographic variables show succeeding birth interval is statistically significant and the children less than 24 months have a higher percentage of underweight and stunted compared to the other groups.

It is seen that stunting is highly significant and has a strong relationship in mother's education $(0.23)$ and the type of toilet facilities available $(0.20)$. The Cramer's V statistics for underweight is generally lower than those of stunting, except in succeeding birth and having electricity in the house. These results support the earlier estimates that more children 0-59 months in Pakistan are stunted (51 percent) than underweight ( 40 percent).

\section{(b) Other Differentials of Growth Pattern-Multivariate Models}

To examine the correlates of poor growth attainment among children under-five years, the multivariate linear regression model has been used. The anthropometric dependent indicators $\mathrm{Ht} / \mathrm{A}$ and $\mathrm{Wt} / \mathrm{A}$ are used as interval variables to focus on patterns of covariations, whereas the categorical independent variables have been converted into dummy variables to estimate for the best model describing the variables related to poor growth attainment among children aged 0-59 months.

Appendix Table 4 shows the operational definitions of the independent variables used in the two models. Tables 3 and $3 \mathrm{a}$ presents the results from the linear regression model for Height/A and Weight/A model. In both the models, the socio-demographic, economic and environmental variables explain a small amount of variation in $\mathrm{Z}$ scores. The reason for the low adjusted $\mathrm{R}^{2}$ values of 0.11 for Height/A and 0.09 for $\mathrm{Wt} / \mathrm{A}$ is because $\mathrm{Z}$-scores data are age standardised. Another possible reason could be that those factors that have a direct effect on growth i.e. food intake by children, or illness are not available in DHS data set. 
Table 3

Multiple Linear Regression Estimates Height-for-Age Covariations for Growth Attainment for Children Aged 0-59 Months, Pakistan, 1990-1991

\begin{tabular}{lrrl}
\hline Variable & \multicolumn{1}{c}{$\mathrm{B}$} & \multicolumn{1}{c}{$\mathrm{T}$} & \multicolumn{1}{l}{ Sig T } \\
\hline Child's Age Squared (Months) & -0.0158 & -4.72 & $.0000^{* *}$ \\
Succeeding Birth Interval $>24$ (Months) & 0.5873 & 7.04 & $.0000^{* *}$ \\
Mother's Current Age (Years) & 0.0151 & 2.33 & $.0256^{*}$ \\
Mother's Education & 0.4833 & 4.90 & $.0000^{* *}$ \\
Toilet & 0.4252 & 4.88 & $.0000^{* *}$ \\
Constant & -2.7690 & -10.83 & .0000 \\
$\mathrm{R}^{2}$ & 0.118 & & \\
Adjusted $\mathrm{R}^{2}$ & 0.116 & & \\
Level of Significance (F) & 0.000 & & \\
\hline
\end{tabular}

Source: This table is the result of original analysis of the PDHS 1990-91 data set. *Significant at $\mathrm{p}=<0.05 ; * *$ Significant at $\mathrm{p}=<0.01$.

Table 3a

Multiple Linear Regression Estimates Weight-for-Age Covariations for Growth Attainment for Children Aged 0-59 Months, Pakistan, 1990-1991

\begin{tabular}{lccl}
\hline Variable & $\mathrm{B}$ & $\mathrm{T}$ & Sig T \\
\hline Child's Squared Age (Months) & -0.0596 & -1.91 & $.0568^{*}$ \\
Succeeding Birth Interval $>24$ (Months) & 0.3501 & 5.75 & $.0000^{* *}$ \\
Mother's Current Age (Years) & 0.0117 & 2.34 & $.0253^{*}$ \\
Mother's Education & 0.2959 & 3.96 & $.0001^{* *}$ \\
Toilet & 0.2911 & 3.65 & $.0003^{* *}$ \\
Has Electricity & 0.2363 & 2.79 & $.0053^{* *}$ \\
Has Refrigerator & 0.2592 & 3.32 & $.0009^{* *}$ \\
Place of Residence (Rural) & -0.2545 & -3.38 & $.0007^{* *}$ \\
Region (Punjab and NWFP) & 0.0678 & 3.038 & $.0024^{*}$ \\
Constant & -2.3923 & -11.88 & .0000 \\
$\mathrm{R}^{2}$ & 0.105 & & \\
Adjusted R & & & \\
Level of Significance (F) & 0.099 & & \\
\hline
\end{tabular}

Source: This table is the result of original analysis of the PDHS 1990-91 data set. *Significant at $\mathrm{p}=<0.05 ; * *$ Significant at $\mathrm{p}=<0.01$. 
Table 3 shows the Height/A model, with four of the variables to have positive association with growth attainment i.e. succeeding birth interval $>24$ months, mother's age, her education and having toilet facilities in the house. In Table 3a the results from the $\mathrm{Wt} / \mathrm{A}$ model show seven variables that have a positive association with growth attainment. They are succeeding birth interval $>24$ months, mother's age, her education and having toilet facilities and electricity in the house, and living in Punjab and NWFP province. Child's age squared in months shows the curvilinear pattern of variation with age. In both $\mathrm{Ht} / \mathrm{A}$ and $\mathrm{Wt} / \mathrm{A}$ models age squared shows negative association with growth attainment, reinforcing the thesis that with age both height and weight declines in under-five children in Pakistan (Figure 2). The positive association of birth interval shows that if there is an interval of more than 24 months both height and weight will improve for the child.

Interestingly mothers having either primary or secondary level education, tend to have greater effect on child's height rather then on the child's weight. For Ht/A and $\mathrm{Wt} / \mathrm{A}$, having flush in the house is the only environmental variable that has a positive association with child's growth attainment. Whereas children living in households having electricity and are from Punjab and NWFP, they have significant and positive correlation to weight. While those from rural areas have a negative and significant effect on the Wt/A. After doing this statistical exercise, another conclusion derived is that there is no association of gender differentials with anthropometric indicators in under-five children in Pakistan.

\section{CONCLUSION AND POLICY IMPLICATION}

The cross-sectional picture of growth attainment obtained from this study is useful for evaluating the overall future nutritional status of the population which can help policy-makers in setting up targets for screening those children at most risk and proposing relevant actions to be taken, while for medical professionals it helps to monitor growth. This study is not relevant from individual perspective of nutritional status as this requires a longitudinal study for growth using incremental growth and growth curves [Maro (1989)]. The anthropometric measurements study is useful for national planning and identification of children at risk in the population.

Some of the possible conclusions derived from this study are to have births by interval of more then two to three years to allow mother's to fully recover, to take proper care of their children, and the child has the parent's attention and is not faced with competition from siblings. There is a need to change those community level covariates that affect the nutritional status of children, for example to make education compulsory, improving the sanitary environment, and promoting smaller family size. The results of this study reinforce and extend to the research that the child's age, education of mother, birth interval, and some household possessions have significant effect on the child's nutritional status both for long run (height-forage) and short term (weight-for-age). 
Planners and policy-makers have to bridge the gap between knowledge and effective implementation. An effective strategy would identify and combine programmes and policy that are likely to have the greatest sustained effect on the nutritional status of a particular group or groups per unit resources spent. Regional priorities need to be assigned to places like Balochistan for improving the living conditions, providing facilities for child health, increasing educational levels and decreasing parity of children for better growth and development among the risk groups. The choice of design and supplementation of nutrition intervention programmes should be made within the context of existing policies and expected changes in them. They must be tailored to each location and time period. Government will not be effective in its efforts to accelerate development in long term sense until optimal child growth development is ensured for the majority. The development of a society depends on the improvement in the condition of its most vulnerable member - the child.

Appendices

Appendix Table 1

Anthropometric Indicators for Children Under-five in South Asian Region (\%)

\begin{tabular}{lccc}
\hline Region & \% Underweight & \% Stunted & \% Wasted \\
\hline Asia & 42.0 & 47.1 & 10.8 \\
South Asia & 60.5 & 60.3 & 17.3 \\
South-East Asia & 37.8 & 43.2 & 7.6 \\
\hline Source: De Onis et al. (1992). & & &
\end{tabular}

Appendix Table 2

Reasons of Non-coverage of Children Aged 0-59 Months, Pakistan 1990-91 (Percent)

\begin{tabular}{ccccccc}
\hline & \multicolumn{5}{c}{ Reasons not Measured } \\
\cline { 2 - 7 } Age & Missing & Sick & Not Present & Refused & Mother Refused & Other \\
\hline $0-5$ & 9.6 & 10.2 & 5.6 & 6.1 & 60.9 & 7.6 \\
$6-11$ & 6.5 & 13.9 & 6.5 & 8.3 & 47.2 & 17.6 \\
$12-23$ & 8.3 & 7.5 & 14.7 & 14.7 & 38.1 & 16.7 \\
$24-35$ & 11.3 & 5.8 & 20.0 & 23.3 & 21.7 & 17.9 \\
$36-47$ & 11.2 & 6.3 & 26.7 & 22.8 & 19.3 & 13.7 \\
$48-59$ & 10.0 & 3.5 & 36.2 & 23.8 & 13.1 & 13.5 \\
Total & 9.8 & 7.1 & 20.3 & 18.0 & 30.4 & 14.4 \\
\hline Source: Computed from Pakistan Demographic and Health Survey 1990-91 data.
\end{tabular}


Appendix Table 3

Percentage Distribution of Children Aged 0-59 Months Measured by Their Sociodemographic, Economic and Environmental Characteristics, Pakistan 1990-91

\begin{tabular}{|c|c|c|c|c|c|}
\hline Characteristics & $\%$ & $\mathrm{~N}$ & Characteristics & $\%$ & $\mathrm{~N}$ \\
\hline Child's Age (Months) & & & Province & & \\
\hline $0-5$ & 11.2 & 456 & Punjab & 34.3 & 1401 \\
\hline $6-11$ & 11.0 & 447 & Sindh & 28.9 & 1179 \\
\hline $12-23$ & 20.4 & 833 & NWFP & 26.9 & 1097 \\
\hline $24-35$ & 20.2 & 844 & Balochistan & 9.9 & 402 \\
\hline $36-47$ & 20.7 & 823 & Region & & \\
\hline $48-59$ & 16.6 & 676 & Rural & 46.3 & 1889 \\
\hline Child's Gender & & & Urban & 53.7 & 2190 \\
\hline Male & 50.2 & 2049 & Mother's Education & & \\
\hline Female & 49.8 & 2030 & No Education & 74.0 & 3017 \\
\hline Mother's Age (Years) & & & Primary & 10.8 & 440 \\
\hline $15-19$ & 3.6 & 148 & Secondary+ & 15.2 & 622 \\
\hline $20-24$ & 19.5 & 796 & Source of Water & & \\
\hline $25-29$ & 31.4 & 1282 & Piped to House & 27.4 & 1115 \\
\hline $30-34$ & 22.2 & 906 & Public Tap & 11.0 & 446 \\
\hline $35-39$ & 14.5 & 593 & Piped on House & 16.1 & 654 \\
\hline $40-44$ & 6.2 & 252 & Well with Pump & 27.6 & 1121 \\
\hline $45-49$ & 2.5 & 102 & Well without Pump & 9.6 & 390 \\
\hline Birth Order & & & Other & 8.4 & 340 \\
\hline 1st Birth & 17.4 & 710 & Type of Sanitation & & \\
\hline 2nd-3rd Birth & 30.8 & 1257 & Flush & 40.3 & 1635 \\
\hline 4th-5th Birth & 24.6 & 1002 & Pit & 11.0 & 448 \\
\hline 6 th + Birth & 27.2 & 1110 & No Facility & 31.7 & 1287 \\
\hline Succeeding Birth Interval & & & Other & 17.0 & 690 \\
\hline First Birth & 17.4 & 711 & & & \\
\hline$<24$ Month & 26.8 & 1094 & & & \\
\hline 25-47 Month & 40.5 & 1652 & & & \\
\hline $48+$ Month & 15.2 & 622 & & & \\
\hline Total & 100.0 & 4079 & Total & 100.0 & 4079 \\
\hline
\end{tabular}

Source: Computed from Pakistan Demographic and Health Survey 1990-91 data set.

Note: Totals may not add up to 100 due to rounding missing values or non-response. $\mathrm{N}=$ Total Number of children aged $0-59$ months. 
Appendix Table 4

Operational Definitions of Independent Variables

\begin{tabular}{ll}
\hline Variables & Definitions \\
\hline Child's Age (Dummies) & Age $0(<1$ Year) Reference Category \\
& Age $1(1$ Year $=1$, Others $=0)$ \\
& Age $2(2$ Year $=1$, Others $=0)$ \\
& Age $3(3$ Year $=1$, Others $=0)$ \\
& Age $4(4$ Year $=1$, Others $=0)$ \\
& Male $=1$, Female $=0$ \\
Child's Gender & Age Group $15-24$ Reference Category \\
Age of Mother (Dummies) & Age Group $15-34=1$, Others $=0$ \\
& Age Group $>35=1$, Others $=0$ \\
Mother's Education & No Education $=0$, Others $=1$ \\
Toilet Facilities & Flush System $=1$, Others $=0$ \\
Place of Residence & Rural $=0$, Urban $=1$ \\
Region & Punjab and NWFP $=0$, Others $=1$ \\
& Punjab $=0$, Others $=1$ \\
\hline
\end{tabular}

\section{REFERENCES}

Ahmed, M. M., and B. Khuda (1986) Breast Feeding in Bangladesh. Journal of Biosocial Science 18: 425-434.

Alderman, H., and M. Garcia (1993) Poverty, Household Food Security, and Nutrition in Rural Pakistan. Washington, D.C.: International Food Policy Research Institute. (Research Report 96).

Alderman, H., and M. Garcia (1994) Food Security and Health Security: Explaining the Levels of Nutritional Status in Pakistan. Economic and Development Cultural Change 42: 485-507.

Andersen, P. P., S. Burger, J. P. Habicht, and K. Peterseon (1993) Protein-energy Malnutrition. In D. Jamison, W. H. Mosley, A. R. Measham and J. L. Bedadilla (eds) Disease Control Priorities in Developing Countries. New York.

Bicego, G. T., and J. T. Boerma (1993) Maternal Education and Child Survival: A Comparative Study of Survey Data from 17 Countries. Social Science and Medicine 36:9 1207-1227.

Brown, L. V., M. F. Zeiltlin, K. E. Peterson, A.M. R. Chowdhury, B.L. Rogers, L. H. Weld, and S. N. Gershoff (1982) Evaluation of the Impact on Weaning Food Messages on Infant Feeding Practices and Child Growth in Rural Nepal. The American Journal of Clinical Nutrition 56: 994-1003.

Caldwell, J. C., P. H. Reddy, and P. Caldwell (1983) The Social Component of Mortality Decline: An Investigation in South India Employing Alternative Methodologies. Population Studies 37: 185-205. 
Chen, L. C., E. Huq, and S. D'Souza (1981) Sex Bias in the Family Allocation of Food and Health Care in Rural Bangladesh. Population Development Review 7:1 $55-70$.

Das Gupta, M. (1987) Selective Discrimination in Rural Punjab. Population Development Review 13:1 77-100.

De Onis, M., Monteiro, C., J. Akre, and G. Clugston (1992) The Worldwide Magnitude of Protein-energy Malnutrition: An Overview from WHO Global Database on Child Growth. Bulletin of the World Health Organisation 71:6 703712.

Dibley, M. J., J. B. Goldsby, N. W. Staehling, and F. Trowbridge (1987) Development of Normalised Curves for the International Growth Reference: Historical and Technical Considerations. American Journal of Clinical Nutrition 46: 736-748.

Dibley, M. J., N. W. Staehling, P. Nieburg, and F. Trowbridge (1987) Interpretation of Z-score Anthropometric Indicators Derived from the International Growth Reference. American Journal of Clinical Nutrition 46: 749-762.

Eveleth, P. B., and J. M. Tanner (1996) Worldwide Variation in Human Growth. London: Cambridge University Press.

Gubhaju, B. B. (1986) Effects of Birth Spacing on Infant and Child Mortality in Rural Nepal. Journal of Biosocial Science 18: 435-447.

Habicht, J. P., R. Martorell, C. Yarbrough, R. M. Malina, and R. E. Klein (1974) Height and Weight Standards for Preschool Children: How Relevant are Ethnic Differences in Growth Potential? Lancet 4: 611-615.

Harton, S. (1988) Birth Order and Child Nutritional Status: Evidence from the Philippines. Economic Development and Cultural Change 30: 341-354.

Joshi, A. R. (1994) Maternal Schooling and Child Health: Preliminary Analysis of the Intervening Mechanisms in Rural Nepal. Health Transition Review 4:1 1-28.

Kielmann, A. (1975) Child and Maternal Health Services in Rural India: The Narangwal Experiment. Integrated Nutrition and Health Care: Vol. I. Baltimore: John Hopkins University Press.

Lutter, C. K., J. O. Mora, J. P. Habicht, K. M. Rasmussen, D. S. Robson, and M. G. Herrera (1990) Age Specific Responsiveness of Weight and Length to Nutritional Supplementation. The American Journal of Clinical Nutrition 1: 359-64.

Martorell, R., J. Leslie, and P. R. Moock (1984) Characteristics and Determinants of Child Nutritional Status in Nepal. The American Journal of Clinical Nutrition 39: 74-86.

McMurray, C. (1996) Cross-sectional Anthropometry: What can it Tell us about the Health of Young Children? Health Transition Review 6: 147-168.

Mora, J. O. (1989) A New Method for Estimating a Standardised Prevalence of Child Malnutrition from Anthropometric Indicators. Bulletin of the World Health Organisation 6:2 133-142. 
Mueller, W. (1986) The Genetics of Size and Shape in Children and Adults. In F. Falkner, and J. M. Tanner (eds) Human Growth: A Comprehensive Treatise. New York: Pleneum Press.

Muhuri, P. K., and S. H. Preston (1991) Mortality Differential by Sex in Bangladesh. Population Development Review 17:13 415-433.

Mull, S. D. (1991) Traditional Perceptions of Marasmus in Pakistan. Social Science and Medicine 32:2 175-191.

Pakistan, Government of (1978) Micro-nutrient Survey of Pakistan 1976-77. Islamabad: Nutrition Cell and Planning and Development Division.

Pakistan, Government of (1992) Pakistan Demographic and Health Survey 1990-91. Islamabad: Federal Bureau of Statistics.

Pebley, R. A., and N. Goldman (1995) Social Inequality and Children's Growth in Guatemala. Health Transition Review 5: 1-20.

Sathar, Z. A. (1985) Infant and Child Mortality in Pakistan-Some Trends and Differentials. Journal of Biosocial Science 175: 351-359.

Senaurer, B., and M. Garcia (1991) Determinants of the Nutrition and Health Status of Preschool Children: An Analysis of Longitudinal Data. Economic Development and Cultural Change 39: 371-389.

UNICEF (1997) The State of the World's Children 1996. New York: Oxford University Press.

UNICEF and Government of Pakistan (1992) Situational Analysis of Children and Women in Pakistan. Islamabad: Pictorial Printers Pvt., Ltd.

Waterlow, J. C., R. Buzina, W. Keller, J. M. Lane, M. Z. Nichaman, and J. M. Tanner (1977) The Presentation and Use of Height and Weight Data for Comparing Status of Groups of Children Under the Age of 10 Years. Bulletin of the World Health Organisation 55:4 489-98.

World Health Organisation (WHO) (1986) Use and Interpretation of Anthropometric Indicators of Nutritional Status. Report of a WHO Working Group. Bulletin of the World Health Organisation 64:6 929-941. 